\title{
Teaching microcontrollers and FPGAs in Quarantine from Coronavirus: Challenges and Prospects
}

\author{
Oleksandr Vorgul \\ ORCID 0000-0002-7659-8796 \\ Department of Microprocessor Technologies and Systems \\ Kharkiv National University of Radio Electronics \\ Kharkiv, Ukraine \\ oleksandr.vorgul@nure.ua \\ Oleg Zubkov \\ ORCID 0000-0002-8528-6540 \\ Department of Microprocessor Technologies and Systems \\ Kharkiv National University of Radio Electronics \\ Kharkiv, Ukraine \\ oleh.zubkov@nure.ua
}

\author{
Iryna Svyd \\ ORCID 0000-0002-4635-6542 \\ Department of Microprocessor Technologies and Systems \\ Kharkiv National University of Radio Electronics \\ Kharkiv, Ukraine \\ iryna.svyd@nure.ua \\ Valerii Semenets \\ ORCID 0000-0001-8969-2143 \\ Department of Microprocessor Technologies and Systems \\ Kharkiv National University of Radio Electronics \\ Kharkiv, Ukraine \\ valery.semenets@nure.ua
}

\begin{abstract}
Modern equipment is becoming more and more complex and education establishment must keep up with it and offer its contribution to the overall progress. The goal of this work is to find the way how to survive on self-isolation and teach microcontrollers and FPGAs. What challenges need to be overcome and what prospects may open up.
\end{abstract}

Keywords-digital signal processing; microprocessor; STM32; programmable logic integrated circuits; learning online

\section{INTRODUCTION}

We were studying and teaching microcontrollers and FPGA. And suddenly a corona virus, quarantine and selfisolation. So we are self-isolated together. The bosses continued to lead the educational process in isolation from teachers, teachers teach in isolation from students, students should have an opportunity and a feedback channel.

Man is a social being, and non-verbal communication methods appeared earlier than speech. What is my point? Work in self-isolation in a trivial form can be reduced to the distribution of teaching materials, which excludes contact in the "teacher-student" system. And the channels, verbal and non-verbal, are closed. Therefore, the upbringing process is actually terminated. Furthermore, for hardware specialties, it is also important that students have, let's say, less opportunities to explore equipment on their own and gain practical experience with real equipment, not its simulation model or with just a theory. And this is not seems to be good.

Despite the fact that the teaching load during selfisolation, according to subjective feelings, is much greater than with the contact form of training, quarantine is something new, while exploring it one can get a new quality and finally improve.

\section{WHAT EXPIRIENCE CAN WE FIND IN THE INTERNET}

Along with self-isolation, it became possible to visit the Coursera platform [1], to participate on the student's part in courses on our interests, to imagine what the creation of such a course in our disciplines will mean, in which direction it can be continued and for fun.

The following were selected as experimental courses:

- Digital Signal Processing from École Polytechnique Fédérale de Lausanne;

- Digital signal processing (in Russian) from the Polytechnic University, St. Petersburg;

- Hardware Description Languages for FPGA;

- Embedded Hadrware and Operation system from the University of Turku.

In each course, the platform offers:

A. Presentation of the course. Like video annotations and self-promotion.

B. The course being structurized on the weekly blocks with summing up the final results and issuing certificates.

\section{Each block contains.}

- Video lectures with video text. Basically, courses on the platform are in English. The courses were not specially selected from universities in different countries, it happened unintentionally. In terms of pronunciation and understanding, the French course is distinguished by perhaps excellent English with a good writing style and the use of Python to illustrate the use of digital processing. Russian course contain a serious theoretical approach and emphasis on MATLAB. Colorado Course - in American English, contrasting with English from Lausanne - has a well-thought-out system of practice. Tasks for modeling HDL nodes are made in the ModelSim program. The simulation result is an HDL file in one of the modeling languages. The course consists of 
two parts, which are the same in structure, but with slightly different presentation styles due to the fact that it is taught by different teachers. The highlight of the Colorado course is the use of a proprietary testbench file format (the student cannot make changes to this file) to validate the assignment. As a result, the verification of the correctness of the scheme is performed on the website of the course compiler using the data file generated by the testbench file.

- There is text below the video lecture. It is synced to the video if the video is running or paused using an underline. The platform provides a translation button for other languages, but it seems that this will appear in the next version.

- During video playback, it is possible to insert small questions for the listener, which stimulates the listener to pay more attention to watching the video, and not to perceive it as background noise. However, correct or incorrect answers to simple questions do not affect the overall rating.

- In addition to video, it is possible to use text materials for classes (files with examples of solved problems, pdf format, scripts with programs illustrations in python).

- After studying the above material, the student is asked to take a test. The compiler of the course has the right to decide whether to allow passing the next item (practical task). Stating the pass level of rating, if there are several tests, the compiler of the course can prohibit the transition to the next part if the previous one has not been completed. So you can build different strategies.

- During the test, you need to complete the task and enter the answer in the form of one number in the whole format, with a fixed point or in the form of a formula. Formulas are introduced in an unusual way, but you can get used to it. As with any other minor problem, entering answers in the form of arrays of numbers can cause problems for listeners. They need to be promptly answered by the course compilers, so the work here requires patience and attention from both sides.

In terms of using a platform that is essentially paid, the interest of the listener is maintained. Apparently, the moderators stimulate the creators of the courses, or competition affects the fact that the course for the student is interesting and well received. The level of the student at the entrance to the course is not checked and in order to fulfill the interestingness and perceptibility one has to choose between the fundamental nature of the course and its popularity.

If the student does not fit into the work schedule, he is offered a transfer of dates of classes. A rather high volume of rhythmic work is required from the listener. The courses, in principle, indicate the time spent in hours and minutes, which, according to the authors, are required to complete a particular task, but, of course, this is very individual.
Conclusion: good idea. Either theory or hardware modeling is proposed for study. Suitable for learning languages (foreign or programming) very well, but this is not our case. When studying electronic circuits, digital or analog, simulation is used. But we need a sound training on hardware issues and it is a completely different story.

\section{HOW GOOD OUR ENVIREMENT WAS BEFORE THE CARANTINE}

With an in-class, contact version of training, an educational institution has the opportunity to spend funds on the purchase of equipment and time for training personnel in order to confirm its relevance in the educational services market, where we are so amicably going. And with the interest of all parties to the process: students, teachers and employers, the listener at the exit should be ready for a smooth and comfortable transition from training to professional activity. Taking into account the realities existing before the quarantine, the experience of the teaching staff and the technical equipment of the staff makes it possible to train a technical specialist from a student [2]. However, an important component of the result is the listener's motivation, which there is still room for improvement.

\section{What Future do WE DREAM ABOUT?}

Our goal is to bring back full laboratory work. Apparently, mixed learning can be a good option - contact with support of the online version, this is possible if you provide layouts for use over the network. This will require changes to the educational process. There is complete certainty here only in one thing: it will not be easier than in the contact version.

After spending nearly four months in deep online, what are our is the general first impression? As for me, I don't like the situation as it is. Let me rename what exactly.

\section{A. Motivation falls.}

Both on the part of the student and on the part of the teachers. It needs to be somehow supported in terrible conditions (no prestige, no decent salary, few points of application of forces are visible, it is hard to see what will happen next).

\section{B. Teacher load has increased.}

Why? But because all the plans, the most individual ones, suggest a stationary regime. Usually we plan in July and we carry out our load the whole year, and the high authorities do not throw additional task as a pleasant surprise. And even there is enough time for scientific work. But we now have a transitional regime. We pass from one stationary state to another. And if the current stationary state can somehow be described, then what will happen in the future is not clear and there are prospects in this: you can try to change something. Let's hope for the best changes in the quality learning environment. 
C. Platforms such as Coursera - it is payable, modern and it works.

For the instructor, this is an additional burden of mastering, course installation (both are once), update and support (both are all the time).

\section{Conducting classes online for a theoretical or praktical course.}

Conducting classes online for a theoretical course, from one side, and hardware like microprocessors and FPGAs, from another side are very different. It is necessary to come up with an active part of the assignment for the student so that it is feasible and not by copypasting or rewriting.

\section{E. With software.}

Three parts of the course. Digital processing is process modeling, STM32 microprocessors and FPGAs [5-11]:

- For digital processing, Matlab is actually the standard. In the installation of the student part of the course, especially online, you have to require students to install programs. There are free, trial, online versions of Matlab. Students balk and look for reasons to get out (here: low motivation!). Instead of Matlab, you can try Octava or Python with libraries that are free software or free. For such software, there are no fundamental problems to implement the same task as for Matlab, but the time (which is not) to enter the mode and develop a digital copy of the course increases.

- STM32. There are several options for proprietary software (free), for many platforms, for Windows, Linux and MAC OS. You can build a course based on paid software with the support of sponsors from production.

- There is no such diversity for FPGAs. Chip and evaluation board manufacturers offer large, complex software, often for a fee $[3,4]$. Simulation options are available for HDL hardware description languages - VHDL and Verilog. So far we are only interested in VHDL. For this case, there exists a student version of ModelSim for Windows that also supports Verilog. As for Linux, GHDL and FreeHDL for Linux, but if you switch to Verilog, you will need to change the software. Mixed projects are problematic.

The university staff has developed a sufficient number of hardware platforms for laboratory workshops and proposed several approaches to solving the problems of remote access to laboratory equipment, presented in [5-15].

Conducting laboratory work on hardware online is a real challenge, which is currently at the stage of testing the optimal use cases.

\section{CONCLUSIONS}

In the days of offline learning, the main form of education was lecture. Its support was a book (textbook and study guide) and consultations. To obtain practical skills we could use practical classes and laboratory works, qualitatively wrapped in preparation for classes by students, preparation of class time material and homework by teachers and high-quality, albeit sometimes tedious, defense of laboratory work. But practical and laboratory ones are nevertheless carried out under the guidance of a teacher, although they contain some of the student's independent work.

In the case of online classes, the lecture in the form of a file is ineffective; lecture-video, with questions-tasks during playback is much better. Information can be dosed in small portions. And leave part of the material in the reference form. A good form of lecture is a presentation with sound, in which the lecturer has the opportunity to draw explanations and graphs on the finished material. The advantage of online learning is that it is quite easy to add multimedia illustrations - video clips or sound effects.

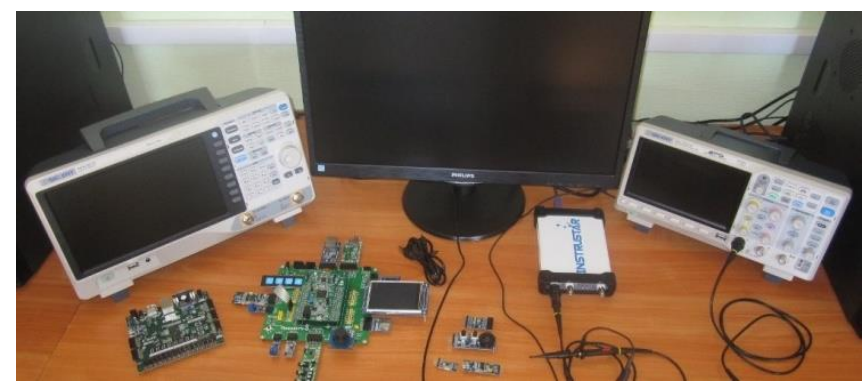

Fig. 1. Laboratory work place.

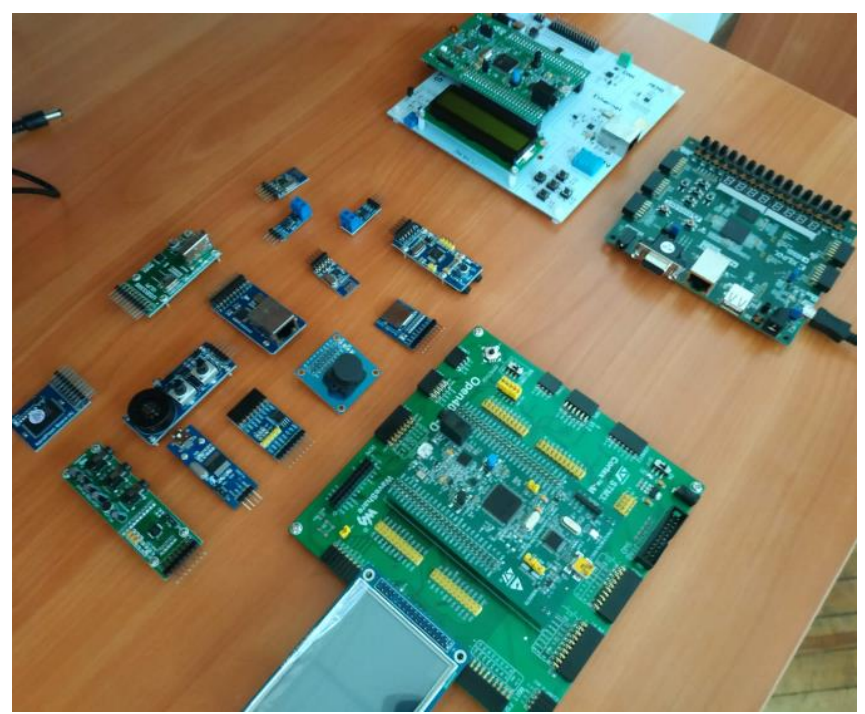

Fig. 2. Laboratory work place [5].

It is more difficult with practical tasks. They should not be long, mandatory for the student and with increasing difficulty from task to task. Laboratory work, like working in software (for a theoretical course) or with hardware (for microcontrollers and FPGAs), is more difficult in a remote implementation. And we really have little experience in conducting classes with hardware and providing students 
with access to the equipment of the department (Fig. 1 and Fig. 2).

Alternatively, in the software, the student writes a program on his remote computer. This will require the installation of specialized software on his computer. But then the student will have the opportunity to perform all operations up to loading the program into the board and incircuit debugging on a remote computer. Upon successful completion of this part, the student should be provided with remote access to the board physically located in the department. And to the measuring instruments correctly connected to the board. To implement such a regime, a sequence of problems arises.

Problem 1. It is necessary to organize the provision of remote access to the student's hardware by means of the operating system or third-party software. Distribute available computers, boards and measurement equipment to students and avoid conflicts.

Problem 2. At the first stage, it is likely that laboratory technicians are required to support such exercises. In addition to mechanical and logical connections, the staff must be able to complete laboratory work in full and be prepared for non-standard situations.

Problem 3. It is necessary to think about whether it is possible to compose and implement tasks for laboratory work with a board, automatically checked online. Or, nevertheless, without physical contact, everything will degenerate into a demonstration to the student on video how someone is doing laboratory work.

Today, there are many organizational and technical issues that have to be solved in the near future to improve the quality of distance education.

\section{REFERENCES}

[1] Coursera. $100 \%$ online education Official website http://www.coursera.org/

[2] F. Morgan et al., "Remote FPGA Lab with Interactive Control and Visualisation Interface," 201121 st International Conference on Field Programmable Logic and Applications, Chania, 2011, pp. 496-499, doi: 10.1109/FPL.2011.98.

[3] Nicole Hemsoth, Timothy Prickett Morgan FPGA Frontiers: New applications in reconfigurable computing. Xilinx, Published by Next Platform Press, 2017, 87 p.

[4] Quartus ${ }^{\circledR}$ Prime Standard Edition Handbook. Intel Corp., 2017.
[5] Valerii Semenets, Liliia Saikivska, Iryna Svyd, Oleksandr Maltsev. Trends in Training Modern Technicians. // First International Scientific and Practical Conference «Theoretical and Applied Aspects of Device Development on Microcontrollers and FPGAs» MC\&FPGA-2019, Kharkiv, Ukraine, July 26-27, 2019, pp. 35-36. doi: 10.35598/mcfpga.2019.013

[6] Iryna Svyd, Oleksandr Maltsev, Oleg Zubkov, Liliia Saikivska. Matlab Use in Design of Digital Systems on the FPGA in CAD Xilinx VIVADO. // First International Scientific and Practical Conference «Theoretical and Applied Aspects of Device Development on Microcontrollers and FPGAs» MC\&FPGA-2019, Kharkiv, Ukraine, July 26-27, 2019, pp. 29-30. doi: 10.35598/mcfpga.2019.010

[7] V. Semenets, I. Svyd and L. Saikivska, "Methods of improving the quality of preparation of technical specialists", inEngineering education: challendes and developments: materials of the IX International Scientific and Methodological Conference, Minsk, Belarus, 2018, pp. 415-416.

[8] V.S. Chumak, I.V. Svyd. Testimonial Modern trends in the training of technical specialists. // Modern education - accessibility, quality, recognition: a collection of scientific papers of the XI International Scientific and Methodological Conference, November 13-14, 2019, Kramatorsk - Kramatorsk: DSEA, 2019. - pp. 245-247

[9] I.V. Svyd, O.V. Litvinenko, O.G. Bilotserkivets. Features of designing digital devices based on Xilinx FPGA in CAD Vivado HLx Design Suite. // Specialized Exhibition "KharkivProm Days. Production and efficiency". Collection of materials of the forum section "Automation, electronics and robotics. Development Strategies and Innovative Technologies". - Kharkiv, KNURE, Exhibition Company ADT, 2019, pp. 43-44.

[10] V. Semenets, "Technical aspects for development laboratory base for learning FPGA and microcontroller systems.", in 10th International Conference The Experience of Designing and Application of CAD Systems in Microelectronics, Lviv-Polyana, Ukraine, 2009, p. 145.

[11] Oleg Zubkov, Iryna Svyd, Oleksandr Maltsev, Liliia Saikivska. Incircuit Signal Analysis in the Development of Digital Devices in Vivado 2018. // First International Scientific and Practical Conference «Theoretical and Applied Aspects of Device Development on Microcontrollers and FPGAs» MC\&FPGA-2019, Kharkiv, Ukraine, July 26-27, 2019. - Kharkiv: 2019. - P. 12-13. DOI: 10.35598/mcfpga.2019.003

[12] V. Semenets, V. Levikin and V. Sayenko, "Research and analysis of the didactic policy of the university in the training of specialists in information technology", Automated control systems and devices, vol. 175, pp. 4-14, 2018.

[13] O. Avrunin, O. Kruk, T. Nosova and V. Semenets, "Technical aspects of the development of virtual laboratory works on technical educational disciplines", Open Education, vol. 3, pp. 11-17, 2008.

[14] V. Kobzev, V. Semenets and V. Filatov, "Components of the information system for monitoring the quality of education in Kharkov National University of Radio Electronics", in 7th Int. scientific and technical conf. Information systems and technologies (IST-2018), Kharkiv-Koblevo, 2018, pp. 51-54.

[15] O. Avrunin, S. Sakalo and V. Semenetc, "Development of up-to-date laboratory base for microprocessor systems investigation", in 19th International Crimean Conference Microwave and Telecommunication Technology CriMiCo - 2009, Sevastopol, Ukraine, 2019, pp. 301-302. 